\title{
Comparison of Artificial Intelligence Techniques for river flow forecasting
}

\author{
M. Firat \\ Research Assistant (PhD), Pamukkale University Civil Engineering Department, Denizli, Turkey \\ Received: 15 May 2007 - Published in Hydrol. Earth Syst. Sci. Discuss.: 6 June 2007 \\ Revised: 15 October 2007 - Accepted: 20 December 2007 - Published: 30 January 2008
}

\begin{abstract}
The use of Artificial Intelligence methods is becoming increasingly common in the modeling and forecasting of hydrological and water resource processes. In this study, applicability of Adaptive Neuro Fuzzy Inference System (ANFIS) and Artificial Neural Network (ANN) methods, Generalized Regression Neural Networks (GRNN) and Feed Forward Neural Networks (FFNN), and Auto-Regressive (AR) models for forecasting of daily river flow is investigated and Seyhan River and Cine River was chosen as case study area. For the Seyhan River, the forecasting models are established using combinations of antecedent daily river flow records. On the other hand, for the Cine River, daily river flow and rainfall records are used in input layer. For both stations, the data sets are divided into three subsets, training, testing and verification data set. The river flow forecasting models having various input structures are trained and tested to investigate the applicability of ANFIS and ANN and AR methods. The results of all models for both training and testing are evaluated and the best fit input structures and methods for both stations are determined according to criteria of performance evaluation. Moreover the best fit forecasting models are also verified by verification set which was not used in training and testing processes and compared according to criteria. The results demonstrate that ANFIS model is superior to the GRNN and FFNN forecasting models, and ANFIS can be successfully applied and provide high accuracy and reliability for daily river flow forecasting.
\end{abstract}

\section{Introduction}

In last decades, the forecasting and modeling of river flow in hydrological processes is quite important to deliver the sustainable use and effective planning and management of

Correspondence to: M. Firat

(mfirat@pamukkale.edu.tr) the water resources. In order to estimate hydrological processes such as precipitation, runoff and change of water level by using existing methods, some parameters such as the physical properties of the watershed and river network and observed detail data are necessary. In the literature, there have been many approaches such as, Box and Jenkins (1970) methods of autoregressive (AR), auto-regressive moving average (ARMA), auto-regressive integrated moving average (ARIMA), autoregressive, moving average with exogenous inputs (ARMAX), generally used for modeling of river flow. Some of the earliest examples of the AR type of stream flow forecast models include Thomas and Fiering (1962) and Yevjevich (1963). These approaches have employed conventional methods of the time series forecasting and modeling (Owen et al., 2001; BuHamra et al., 2003; Zhang, 2003; Mohammadi et al., 2006; Arena et al., 2006; Komornik et al., 2006; Toth et al., 2000). Artificial neural networks (ANN) have been recently accepted as an efficient alternative tool for modeling of complex hydrologic system to the conventional methods and widely used for prediction. Some specific applications of ANN to hydrology include modeling rainfallrunoff process (Sajikumar et al., 1999), river flow forecasting (Dibike et al., 2001; Chang et al., 2002; Sudheer and Jain; 2004; Dawson et al., 2002), sediment transport prediction (Firat and Güngör, 2004), and sediment concentration estimation (Nagy et al., 2002). The ASCE Task Committee reports (2000) did a comprehensive review of the applications of ANN in hydrological forecasting context. Jain and Kumar (2007) proposed a new hybrid time series neural network model that is capable of exploiting the strengths of traditional approaches and ANN. Tingsanchali and Gautam (2000) applied ANN and stochastic hydrologic models to forecast the flood in two river basins in Thailand. GRNN method have also been used for many specific studies $(\mathrm{Ci}-$ gizoglu, 2005; Cigizoglu and Alp, 2006; Kim et al., 2004; Ramadhas et al., 2006; Celikoglu and Cigizoglu, 2007; Celikoglu, 2006). On the other hand, Fuzzy Logic (FL) method

Published by Copernicus Publications on behalf of the European Geosciences Union. 


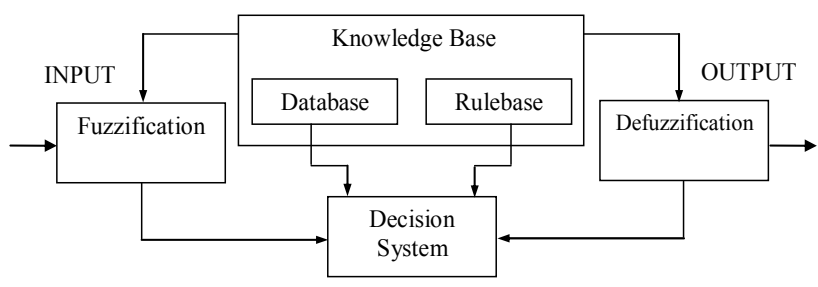

Fig. 1. The general structure of the Fuzzy Inference System.

was first developed to explain the human thinking and decision system by Zadeh (Şen, 2001). Several studies have been carried out using fuzzy logic in hydrology and water resources planning (Chang et al., 2001; Liong et al., 2000; Mahabir et al., 2000; Nayak et al., 2004a; Şen and Altunkaynak, 2006). Recently, Adaptive Neuro-fuzzy inference system (ANFIS), which consists of the ANN and FL methods, have been used for several application such as, database management, system design and planning/forecasting of the water resources (Chen et al., 2006; Chang et al., 2006; Nayak et al., 2004b; Firat, 2007; Firat and Güngör, 2007; Kisi, 2006).

The main purpose of this study is to investigate the applicability and capability of ANFIS, ANN and AR methods for modeling of daily river flow. To verify the application of these approaches, two case study areas, Seyhan River and Cine River, were chosen. For the Seyhan River, daily river flow records measured at the time period 1986-2000 years are used to establish the river flow forecasting models. For the Cine River, daily river flow and rainfall records measured between 1992-2000 years are used. For both case study, all models are trained and tested and performances of models are compared with observation records. The best fit input structure and method is determined according to performances. Then the best fit models for Seyhan River and Cine River is verified using verification data set to evaluate the performances of models.

\section{Adaptive Neuro Fuzzy Inference System (ANFIS)}

The FL approach is based on the linguistic uncertainly expression rather than numerical uncertainty. Since Zadeh (1965) proposed the FL approach to describe complicated systems, it has become popular and has been successfully used in various engineering problems, (Chen et al., 2006; Chang et al., 2001; Liong et al., 2000; Mahabir et al., 2000; Nayak et al., 2004a; Firat, 2007; Nayak et al., 2004b; Şen, 2001). Fuzzy inference system (FIS) is a rule based system consists of three conceptual components. These are: (1) a rule-base, containing fuzzy if-then rules, (2) a data-base, defining the Membership Function (MF) and (3) an inference system, combining the fuzzy rules and produces the system results (Şen, 2001). The first phase of FL modeling is the determination of MFs of input -output variables, the second

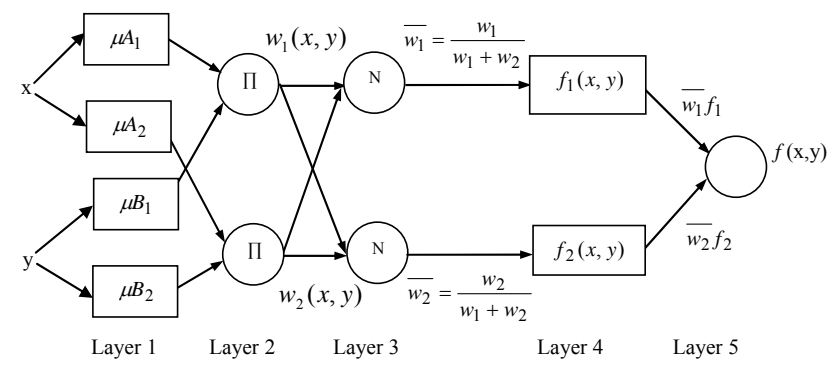

Fig. 2. The scheme of Adaptive Neuro-Fuzzy Inference System.

phase is the construction of fuzzy rules and the last phase is the determination of output characteristics, output MF and system results. A general structure of fuzzy system is demonstrated in Fig. 1.

ANFIS consisting of the combination of the ANN and the FL has been shown to be powerful in modeling numerous processes such as rainfall-runoff modeling and real-time reservoir operation (Chen et al., 2006; Chang et al., 2006; Firat and Güngör, 2007). ANFIS uses the learning ability of ANN to define the input-output relationship and construct the fuzzy rules by determining the input structure. The system results were obtained by thinking and reasoning capability of the fuzzy logic. There are two types of FISs, SugenoTakagi FIS and Mamdani FIS, in literature. In this study, Sugeno Takagi FIS is used for modeling of daily river flow. The most important difference between these systems is the definition of the consequent parameter. The consequence parameter in Sugeno FIS is a linear equation, called first-order Sugeno FIS, or constant coefficient, zero-order Sugeno FIS (Jang et al., 1997). It is assumed that the fuzzy inference system includes two inputs, $x$ and $y$, and one output, $z$. For the first-order Sugeno FIS, typical two rules can be expressed as;

Rule 1: IF $x$ is $A_{1}$ and $y$ is $B_{1}$

$$
\text { THEN } f_{1}=p_{1} * x+q_{1} * y+r_{1}
$$

Rule 2: IF $x$ is $A_{2}$ and $y$ is $B_{2}$

$$
\text { THEN } f_{2}=p_{2} * x+q_{2} * y+r_{2}
$$

where, $x$ and $y$ are the crisp inputs to the node $i, A_{i}$ and $B_{i}$ are the linguistic labels as low, medium, high, etc., which are characterized by convenient MFs and finally, $p_{i}, q_{i}$ and $r_{i}$ are the consequence parameters. The structure of this FIS is shown in Fig. 2.

Input notes (Layer 1): Each node in this layer generates membership grades of the crisp inputs which belong to each of convenient fuzzy sets by using the MFs. Each node's output $O_{i}^{1}$ is calculated by:

$$
\begin{aligned}
& O_{i}^{1}=\mu_{A_{i}}(x) \text { for } i=1,2 \\
& O_{i}^{1}=\mu_{B_{i-2}}(y) \text { for } i=3,4
\end{aligned}
$$


where $\mu_{A_{i}}$ and $\mu_{B_{i}}$ are the MFs for $A_{i}$ and $B_{i}$ fuzzy sets, respectively. In this study, the Gauss MF is used, as;

$O_{i}^{1}=\mu_{A_{i}}(x)=e^{\frac{-(x-c)^{2}}{2 \sigma^{2}}}$

Rule nodes (Layer 2): In this layer, the AND/OR operator is applied to get one output that represents the results of the antecedent for a fuzzy rule, that is, firing strength. The outputs of the second layer, called firing strengths $O_{i}^{2}$, are the products of the corresponding degrees obtained from the layer 1, named as $w$ as follows;

$O_{i}^{2}=w_{i}=\mu_{A i}(x) \mu_{B i}(y), \quad i=1,2$

Average nodes (Layer 3): Main target is to compute the ratio of firing strength of each $i$ th rule to the sum firing strength of all rules. The firing strength in this layer is normalized as;

$O_{i}^{3}=\bar{w}_{i}=\frac{w_{i}}{\sum_{i} w_{i}} \quad i=1,2$

Consequent nodes (Layer 4): The contribution of $i^{\text {th }}$ rule towards the total output or the model output and/or the function defined is calculated by Eq. (5);

$O_{i}^{4}=\bar{w}_{i} f_{i}=\bar{w}_{i}\left(p_{i} x+q_{i} y+r_{i}\right) \quad i=1,2$

$\bar{w}_{i}$ is the $i$ th node output from the previous layer as demonstrated in the third layer. $\left\{p_{i}, q_{i}, r_{i}\right\}$ is the parameter set in the consequence function and also the coefficients of linear combination in Sugeno inference system.

Output nodes (Layer 5): This layer is called as the output nodes in which the single node computes the overall output by summing all incoming signals and is also the last step of the ANFIS. The output of the system is calculated as;

$$
\begin{aligned}
f(x, y) & =\frac{w_{1}(x, y) f_{1}(x, y)+w_{2}(x, y) f_{2}(x, y)}{w_{1}(x, y)+w_{2}(x, y)} \\
& =\frac{w_{1} f_{1}+w_{2} f_{2}}{w_{1}+w_{2}}
\end{aligned}
$$

$Q_{i}^{5}=f(x, y)=\sum_{i} \bar{w}_{i} \cdot f_{i}=\bar{w}_{i} f_{1}+\bar{w}_{i} f_{2}=\frac{\sum_{i} w_{i} f_{i}}{\sum_{i} w_{i}}$

The objective is to train adaptive networks for having convenient unknown functions given by training data and finding the proper value of the input and output parameters. For this aim, ANFIS applies the hybrid-learning algorithm, consists of the combination of the "gradient descent" and "the leastsquares" methods. The gradient descent method is used to assign the nonlinear input parameters, as the least-squares method is employed to identify the linear output parameters. The detailed algorithm and mathematical background of these algorithms can be found in Jang et al. (1997).

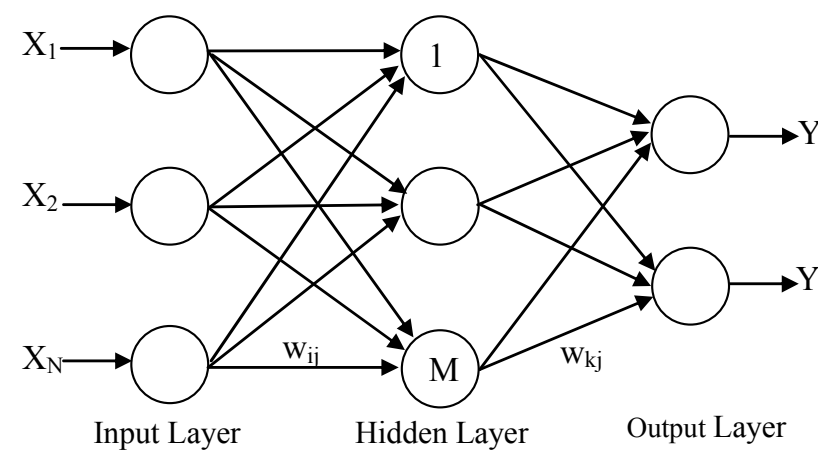

Fig. 3. General structure of a FFNN.

\section{Artificial Neural Networks}

An ANN can be defined as a system or mathematical model consisting of many nonlinear artificial neurons running in parallel which can be generated as one or multiple layered. In this study, GRNN and FFNN methods are used for forecasting of daily river flow.

\subsection{Feed Forward Neural Networks (FFNN)}

A FFNN consists of at least three layers, input, output and hidden layer. The number of hidden layers and neurons in hidden layer are determined by trial and error method. The schematic diagram of a FFNN is shown in Fig. 3. Each neuron in a layer receives weighted inputs from a previous layer and transmits its output to neurons in the next layer. The summation of weighted input signals is calculated by Eq. (8) and is transferred by a nonlinear activation function given in Eq. (9). The responses of network are compared with the observation results and the network error is calculated with Eq. (10).

$Y_{\text {net }}=\sum_{i=1}^{N} X_{i} \cdot w_{i}+w_{0}$

$Y_{\text {out }}=f\left(Y_{\text {net }}\right)=\frac{1}{1+e^{-Y_{\text {net }}}}$

$J_{r}=\frac{1}{2} \cdot \sum_{i=1}^{k}\left(Y_{\text {obs }}-Y_{\text {out }}\right)^{2}$

$Y_{\text {out }}$ is the response of neural network system, $f\left(Y_{\text {net }}\right)$ is the nonlinear activation function, $Y_{\text {net }}$ is the summation of weighted inputs, $X_{i}$ is the neuron input, $w_{i}$ is weight coefficient of each neuron input, $w_{0}$ is bias, $J_{r}$ is the error between observed value and network result, $Y_{\text {obs }}$ is the observation output value. In this study, the back propagation learning algorithm, the supervised learning and sigmoid activation function are used in training and testing of models. 


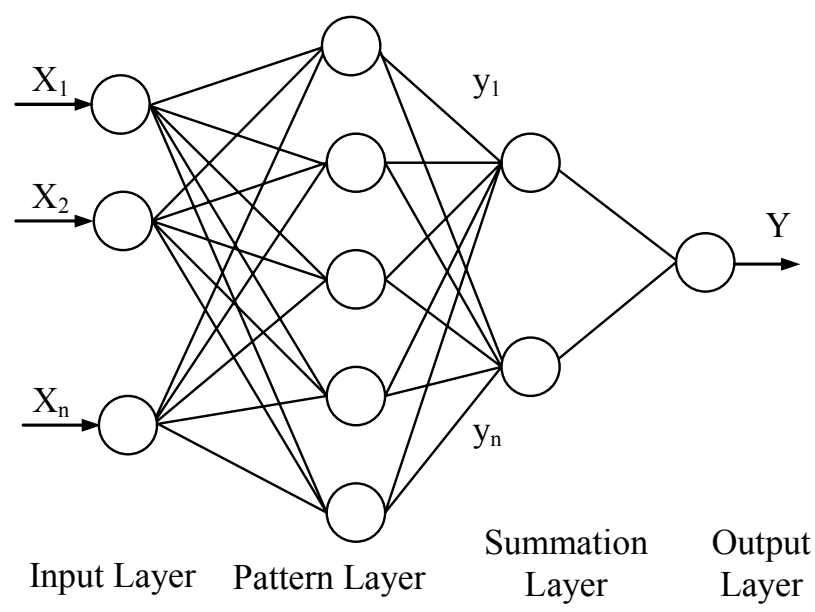

Fig. 4. The general structure of a GRNN.

\subsection{Generalized Regression Neural Networks (GRNN)}

A GRNN is a variation of the radial basis neural networks, which is based on kernel regression networks (Cigizoglu, 2005; Cigizoglu and Alp, 2006). A GRNN doesn't require an iterative training procedure as back propagation networks. A GRNN consists of four layers: input layer, pattern layer, summation layer and output layer as shown in Fig. 4.

The number of input units in input layer depends on the total number of the observation parameters. The first layer is connected to the pattern layer and in this layer each neuron presents a training pattern and its output. The pattern layer is connected to the summation layer. The summation layer has two different types of summation, which are a single division unit and summation units. The summation and output layer together perform a normalization of output set. In training of network, radial basis and linear activation functions are used in hidden and output layers. Each pattern layer unit is connected to the two neurons in the summation layer, $S$ and $D$ summation neurons. $S$ summation neuron computes the sum of weighted responses of the pattern layer. On the other hand, $D$ summation neuron is used to calculate unweighted outputs of pattern neurons. The output layer merely divides the output of each S-summation neuron by that of each $D$ summation neuron, yielding the predicted value to an unknown input vector $\boldsymbol{x}$ as (Kim et al., 2004);

$Y_{i}^{\prime}=\frac{\sum_{i=1}^{n} y_{i} \cdot \exp \left[-D\left(x, x_{i}\right)\right]}{\sum_{i=1}^{n} \exp \left[-D\left(x, x_{i}\right)\right]}$

$D\left(x, x_{i}\right)=\sum_{k=1}^{m}\left(\frac{x_{i}-x_{i k}}{\sigma}\right)^{2}$

$y_{i}$ is the weight connection between the $i$ th neuron in the pattern layer and the $S$-summation neuron, $n$ is the number of the training patterns, $D$ is the Gaussian function, $m$ is the number of elements of an input vector, $x_{k}$ and $x_{i k}$ are the $j$ th element of $x$ and $x_{i}$, respectively, $\sigma$ is the spread parameter, whose optimal value is determined experimentally.

\section{Auto-Regressive Model}

In the traditional analysis techniques, the data set must be divided to periodical component, trend component, internal dependent component and independent (random) components. Trend is the evidence of the increase or decrease of process parameters (mean and standard deviation) by time. It is understood that there is a periodical component when the parameters of the process show variation in a determined period. BOX-COX transformation was applied to the data to converge the data to normal distribution. The periodicity of the daily means and standard deviations were calculated by using Fourier series to arrange the periodicity in the data.

$D N Y(t)=\frac{D Y(t)-\overline{D Y}}{\sigma_{D Y}}$

where $D N Y(t)$ is the normalized time series variable, $D Y(t)$ is the original time series variable, $\overline{D Y}$ is the mean of the original time series data and $\sigma_{D Y}$ is the standard deviation of the original time series data. In order to get more accurate and reliable evaluation and comparison the best fit input structures were used to forecast the daily river flow by using AR models. The structure of AR model for Seyhan River and ARX (Auto Regressive with eXogenous inputs) model for Cine River was given in Eqs. (14) and (15).

$$
\begin{aligned}
& Q(t)=\sum_{i=1}^{N} \alpha_{i} Q(t-i)+\varepsilon(t) \\
& Q(t)=\sum_{i=1}^{N} \alpha_{i} Q(t-i)+\sum_{k=1}^{m} \alpha_{k} P(t-k)+\varepsilon(t)
\end{aligned}
$$

where, $Q(t)$ is the daily river flow, $Q(t-i)$ is the river flow at $(t-i)$ time, $\alpha$ is the auto-regressive parameter to be determined $(i)$ is an index representing the order of AR model, $P(t-k)$ is the rainfall at $(t-k)$ time, $\alpha_{k}$ is the auto-regressive parameter and $\varepsilon(t)$ is the random error. The optimal values of ARX model parameters were estimated using the MATLAB Identification Toolbox and identification data set. The model parameters are selected using Akaike's final prediction error (FPE) criterion.

\section{Study area and available data}

To illustrate the applicability of the ANFIS and ANN methods, two river stations, Seyhan River and Cine River, were chosen as case study. Seyhan River, located in South of Turkey, between $36^{\circ} 33^{\prime}$ and $39^{\circ} 12^{\prime} \mathrm{N}$ and $34^{\circ} 24^{\prime}-36^{\circ} 56^{\prime} \mathrm{E}$, 


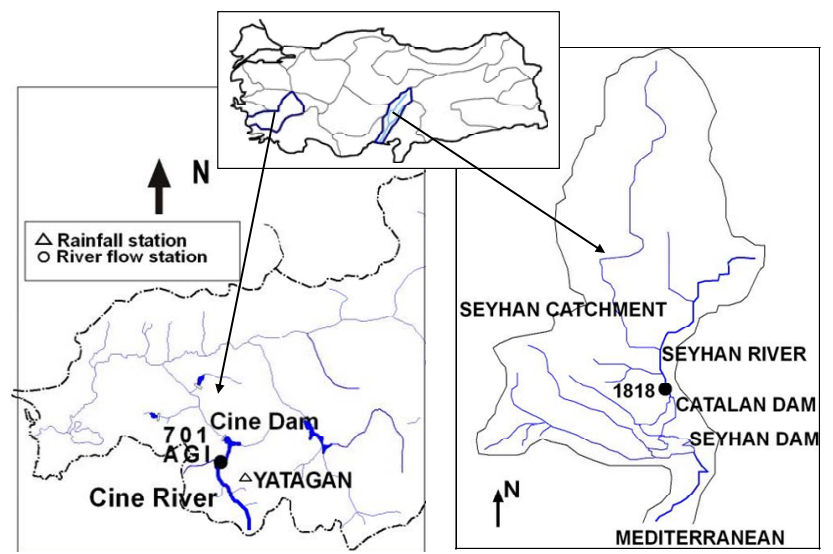

Fig. 5. Study areas.

is chosen as case study area. Seyhan River has lengthy of $560 \mathrm{~km}$ and the drainage area of $20600 \mathrm{~km}^{2}$. Climatic conditions in the area are typical Mediterranean climate and annual average rainfall is $600 \mathrm{~mm}$. There are two big dams, Seyhan and Catalan, which are very important for region on Seyhan River catchment. There is one river flow gauging station on the main branch of Seyhan River, Üçtepe gauging station (no.1818), located upstream of the Çatalan and Seyhan dams. This station is located on $352717 \mathrm{E}$ and $372525 \mathrm{~N}$ coordinates and has drainage area of $13740.60 \mathrm{~km}^{2}$. Cine River located in the west of Turkey has lengthy of $359 \mathrm{~km}$. There is one river flow gauging station on the Cine River, Kayirli station (no. 701), located upstream of Cine dam. Kayirli station located on $280750 \mathrm{E}$ and $372516 \mathrm{~N}$ coordinates has drainage area of $948 \mathrm{~km}^{2}$ and annual runoff potential of river is $651 \mathrm{hm}^{3}$. There is one rainfall station (Yatagan station) located upstream of the Kayirli river flow station. Annual average rainfall and temperature of this region is about $671 \mathrm{~mm}$. and $16^{\circ} \mathrm{C}$, respectively. The locations of these stations are shown in Fig. 5.

\section{River flow forecasting}

\subsection{Input variables}

The river flow process in any cross section of river system can be characterized as the function of various variables such as, spatial and temporal distribution of rainfall, catchment and river physical characteristics. The relationship of between river flow and influential variables can be expressed by;

$Q(t)=f(X(t))+\varepsilon_{t}$

where, $Q(t)$ denotes the river flow in any cross section of river system, $\varepsilon_{t}$ is the random error, $X(t)$ is the input vector, which may include many variables such as antecedent flow
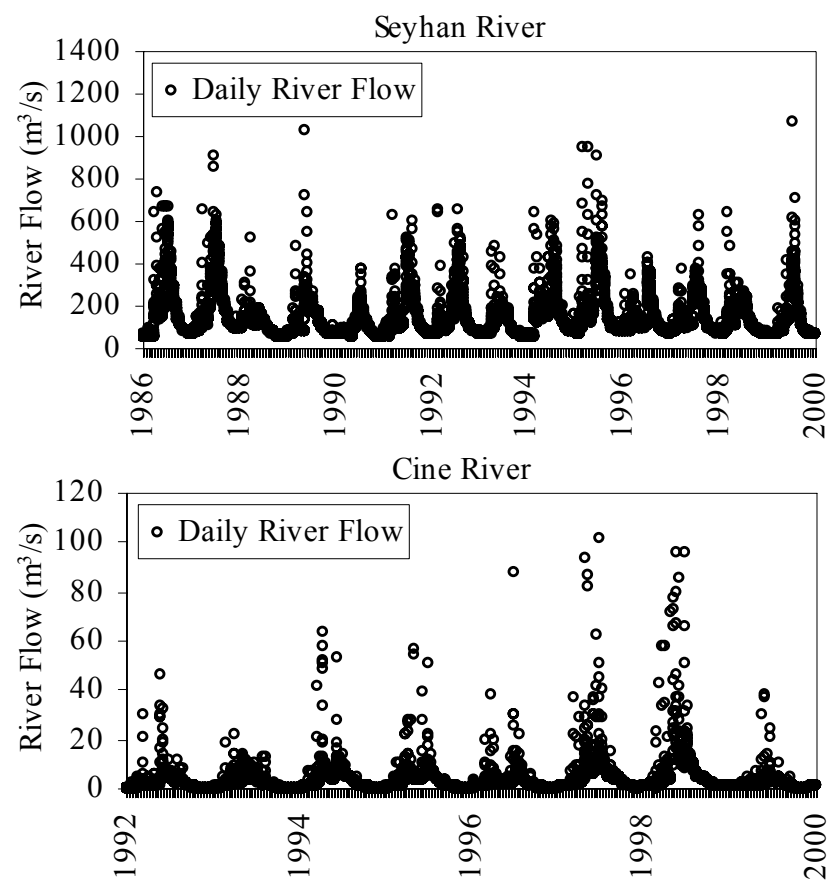

Fig. 6. River flow records.

and rainfall data and other hydroclimatic variables at various time lags but in the present application, for the Seyhan river, it consists of combinations of antecedent daily river flow records, whereas for the Cine River, it consists of daily river flow and rainfall records are used in input layer. It is evident that the training data sets should cover all the characters of the problem in order to get effective estimation. For the Seyhan River, the data set includes total 5114 daily river flow data and data set is divided into three subsets, training, testing and verification data set. The training data set includes total 2922 daily river flow records measured at the time period 1986-1994 years, the testing data set consists of 1461 daily river data records measured between in 1994 and 1998 years. The verification data set consists of 731 daily river data records measured at the time 1998-2000 years. For the Cine River, total 2923 daily river flow and daily rainfall data was collected at the time period 1992 and 2000 years. The training set includes total 1464 data records at the time period 1992-1996 years, testing set consists of 730 data records measured between in 1996 and 1998 years. 731 daily river data records measured at the time 1998-2000 years was chosen for the verification of models. Figure 6 shows daily flow records of Seyhan River and Cine River. The minimum value; $x_{\min }$, maximum value; $x_{\max }$, mean; $\bar{x}$, standard deviation; $s_{x}$, variation coefficient $c_{v x}$, skewness coefficient; $c_{s x}$, for total observed data sets are given in Table 1 . 
Table 1. The statistical parameters for data sets.

\begin{tabular}{llccccc}
\hline Variable & Data Set & $x_{\min }$ & $x_{\max }$ & $\bar{x}$ & $s_{x}$ & $c_{s x}$ \\
\hline \multirow{5}{*}{$Q(t)\left(\mathrm{m}^{3} / \mathrm{s}\right)$} & Seyhan River (Uctepe Station) & & & \\
& Training (01.10.1986-30.09.1994) & 54.00 & 912.00 & 141.41 & 109.14 & 2.39 \\
& Testing (01.10.1994-30.09.1998) & 56.00 & 778.00 & 160.96 & 111.34 & 2.05 \\
& Verification $(01.10 .1998-30.09 .2000)$ & 60.80 & 712.00 & 134.52 & 95.42 & 2.37 \\
\hline \multicolumn{2}{c}{ Cine River (Kayirli Station) } & & & \\
\hline \multirow{3}{*}{$Q(t)\left(\mathrm{m}^{3} / \mathrm{s}\right)$} & Testing (01.10.1996-30.09.1998) & 0.097 & 62.94 & 3.39 & 6.05 & 5.28 \\
& Verification $(01.10 .1998-30.09 .2000)$ & 0.094 & 96.00 & 5.51 & 11.39 & 4.63 \\
\hline \multirow{3}{*}{$P(\mathrm{~mm})$} & Training (01.10.1992-30.09.1996) & 0.00 & 95.30 & 2.42 & 7.93 & 5.56 \\
& Testing (01.10.1996-30.09.1998) & 0.00 & 103.15 & 2.86 & 9.97 & 5.32 \\
& Verification $(01.10 .1998-30.09 .2000)$ & 0.00 & 59.40 & 2.26 & 6.73 & 4.27 \\
\hline
\end{tabular}

Table 2. Cross correlations between variables.

\begin{tabular}{|c|c|c|c|c|c|c|c|}
\hline \multicolumn{8}{|c|}{ Seyhan River } \\
\hline & $Q(t-1)$ & $Q(t-2)$ & $Q(t-3)$ & $Q(t-4)$ & $Q(t-5)$ & $Q(t-6)$ & $Q(t-7)$ \\
\hline$Q(t)$ & 0.984 & 0.963 & 0.945 & 0.930 & 0.917 & 0.906 & 0.897 \\
\hline \multicolumn{8}{|c|}{ Cine River } \\
\hline & $Q(t-1)$ & $Q(t-2)$ & $Q(t-3)$ & $P(t)$ & $P(t-1)$ & $P(t-2)$ & \\
\hline$Q(t)$ & 0.97 & 0.95 & 0.93 & 0.45 & 0.40 & 0.38 & \\
\hline
\end{tabular}

\subsection{Model structure}

One of the most important steps in developing a satisfactory forecasting model is the selection of the input variables. Hence, cross- correlations between input and output variables are calculated in order to apply the methods for modeling (Table 2). Different combinations of the antecedent flows of river flow gauge station are used to construct the appropriate input structure. The structures of models for Seyhan River and Cine River are shown in Tables 3 and 4, respectively.

Where $Q_{t}$ represents the River flow at time $(t)$, $Q(t-1), \ldots Q(t-n)$ are the river flow respectively at times $(t-1) \ldots(t-n) . \quad P_{t}$ represents the rainfall at time $(t)$, $P(t-1), \ldots P(t-n)$ are the rainfall respectively at times $(t-1) \ldots(t-n)$. The training and testing experiments with ANFIS and ANN methods are carried out considering various input layer structures. The performances of the models both training and testing data are evaluated and compared according to Correlation Coefficient (CORR), Efficiency (E), Root Mean Square Error (RMSE), Mean Error in forecasting the maximum peak discharge value (\%MERR) and the maximum percentage error (\%MP).
$\mathrm{CORR}=\frac{\sum_{t=1}^{N}\left(Q_{D(t)}-\overline{Q_{D}}\right) \cdot\left(Q_{Y(t)}-\overline{Q_{Y}}\right)}{\sqrt{\sum_{t=1}^{N}\left(Q_{D(t)}-\overline{Q_{D}}\right)^{2} \cdot\left(Q_{Y(t)}-\overline{Q_{Y}}\right)^{2}}}$

$\mathrm{E}=\frac{\mathrm{E}_{1}-\mathrm{E}_{2}}{\mathrm{E}_{1}}$

$\mathrm{E}_{1}=\sum_{t=1}^{N}\left(Q_{D(t)}-\overline{Q_{D}}\right)^{2}, \quad \mathrm{E}_{2}=\sum_{t=1}^{N}\left(Q_{Y}(t)-Q_{D(t)}\right)^{2}$

$\operatorname{RMSE}=\left[\sum_{t=1}^{N} \frac{\left(Q_{D(t)}-Q_{Y(t)}\right)^{2}}{N}\right]^{0.5}$

$\%$ MERR $=\left(\frac{Q_{Y_{\max }}-Q_{D_{\max }}}{Q_{D_{\max }}}\right) .100$

$\% \mathrm{MP}=\left(\frac{Q_{Y}-Q_{D}}{Q_{D}}\right)_{\max } \cdot 100$

where, $Q_{Y}$ is the forecasted river flow, $Q_{D}$ is the field observation of river flow, $\overline{Q_{Y}}$ is the average of the forecasted river flows, $\overline{Q_{D}}$ is the average of the observation river flow. 
Table 3. The structure of the models for forecasting of Seyhan river flow.

\begin{tabular}{llc}
\hline Model & Input structure & Output \\
\hline R-I M1 & $Q(t-1)$ & $Q(t)$ \\
R-I M2 & $Q(t-1) Q(t-2)$ & $Q(t)$ \\
R-I M3 & $Q(t-1) Q(t-2) Q(t-3)$ & $Q(t)$ \\
R-I M4 & $Q(t-1) Q(t-2) Q(t-3) Q(t-4)$ & $Q(t)$ \\
R-I M5 & $Q(t-1) Q(t-2) Q(t-3) Q(t-4) Q(t-5)$ & $Q(t)$ \\
R-I M6 & $Q(t-1) Q(t-2) Q(t-3) Q(t-4) Q(t-5) Q(t-6)$ & $Q(t)$ \\
R-I M7 & $Q(t-1) Q(t-2) Q(t-3) Q(t-4) Q(t-5) Q(t-6) Q(t-7)$ & $Q(t)$ \\
\hline
\end{tabular}

Table 4. The structure of the models for forecasting of Cine river flow.

\begin{tabular}{clc}
\hline Model & Input structure & Output \\
\hline R-II M1 & $P(t)$ & $Q(t)$ \\
R-II M2 & $P(t) P(t-1)$ & $Q(t)$ \\
R-II M3 & $P(t) P(t-1) P(t-2)$ & $Q(t)$ \\
R-II M4 & $Q(t-1) P(t)$ & $Q(t)$ \\
R-II M5 & $Q(t-1) P(t) P(t-1)$ & $Q(t)$ \\
R-II M6 & $Q(t-1) P(t) P(t-1) P(t-2)$ & $Q(t)$ \\
R-II M7 & $Q(t-1) Q(t-2) P(t)$ & $Q(t)$ \\
R-II M8 & $Q(t-1) Q(t-2) P(t) P(t-1)$ & $Q(t)$ \\
R-II M9 & $Q(t-1) Q(t-2) P(t) P(t-1) P(t-2)$ & $Q(t)$ \\
R-II M10 & $Q(t-1) Q(t-2) Q(t-3) P(t)$ & $Q(t)$ \\
R-II M11 & $Q(t-1) Q(t-2) Q(t-3) P(t) P(t-1)$ & $Q(t)$ \\
R-II M12 & $Q(t-1) Q(t-2) Q(t-3) P(t) P(t-1) P(t-2)$ & $Q(t)$ \\
\hline
\end{tabular}

The correlation coefficient is a commonly used statistic and provides information on the strength of linear relationship between the observed and the computed values. The efficiency (E) is one of the widely employed statistics to evaluate model performance. An efficiency of $1(\mathrm{E}=1)$ corresponds to a perfect match of modeled discharge to the observed data. It should be noted that Nash-Sutcliffe efficiencies can also be used to quantitatively describe the accuracy of model outputs other than discharge. This method can be used to describe the predicative accuracy of other models as long as there is observed data to compare the model results. The values of CORR and E close to 1.0 indicate good model performance. RMSE evaluates the residual between measured and forecasted river flow. RMSE is a frequently-used measure of the difference between values predicted by a model or an estimator and the values actually observed from the thing being modeled or estimated. These differences are also called residuals. Theoretically, if this criterion equals zero then model represents the perfect fit, which is not possible at all. The \%MERR is the error in forecasting the maximum peak discharge value and it is useful in designing dams and bridges. The MP is an unbiased statistic for measuring the predictive capability of a model. It is clear that small \%MP values indicate better model performance

\subsubsection{ANFIS Model}

In this study firstly, the seven models having various input variables are trained and tested by ANFIS method and the performances of models for river flow forecasting models are compared and evaluated based on training and testing performances. The best fit model structure is determined according to criteria of performance evaluation. The performances of the ANFIS models for both stations are shown in Fig. 7.

As can be seen in Fig. 7, the ANFIS models are evaluated based on their performance in testing sets. The models have shown significant variations in the criteria of the performance evaluation given in Fig. 7. Firstly, for Seyhan River, it shows that the lowest value of the RMSE and the highest values of the E and CORR are R-I M2 ANFIS model. R-I M2 ANFIS model, which consists of two antecedent flows in input, has shown the highest efficiency, correlation and the minimum RMSE and R-I M2 was selected as the best-fit model for modeling of Seyhan river flow in the Seyhan catchment. Secondly, comparing the performances of ANFIS model for Cine River, it is seen that R-II M5 ANFIS model, which has three input variables in input layer, has shown the best fit performance. The highest values of $\mathrm{E}$ and CORR criteria were obtained from R-II M5 ANFIS model. According to criteria, 

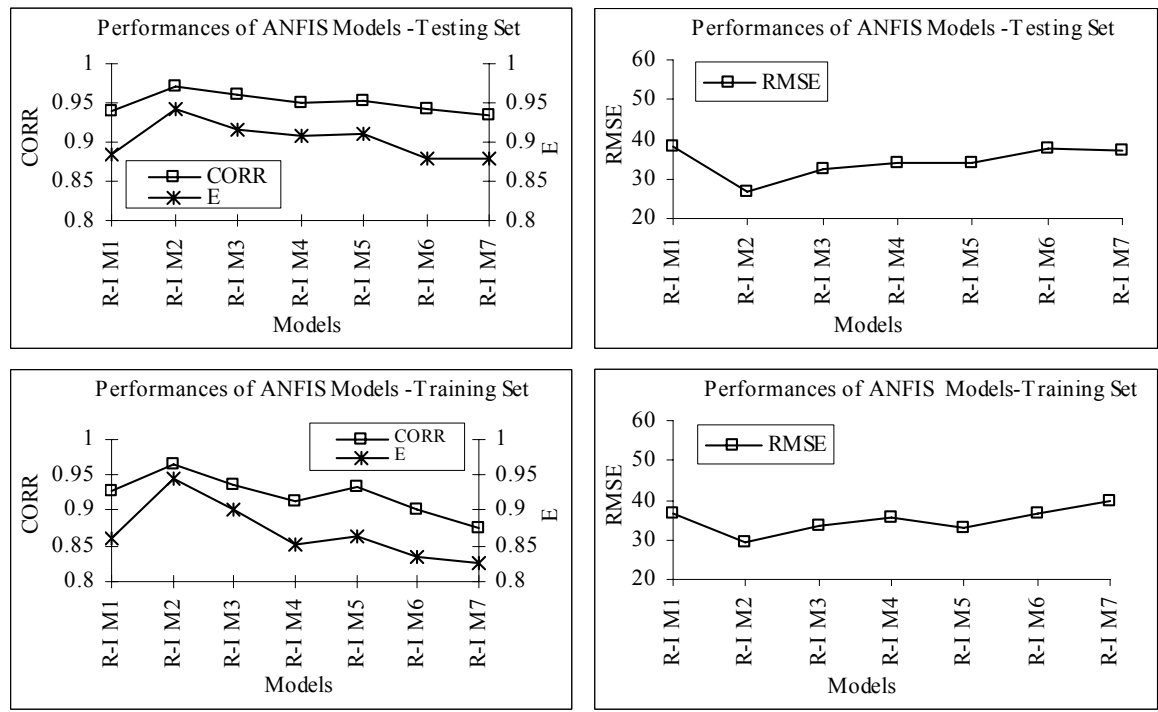

(a)
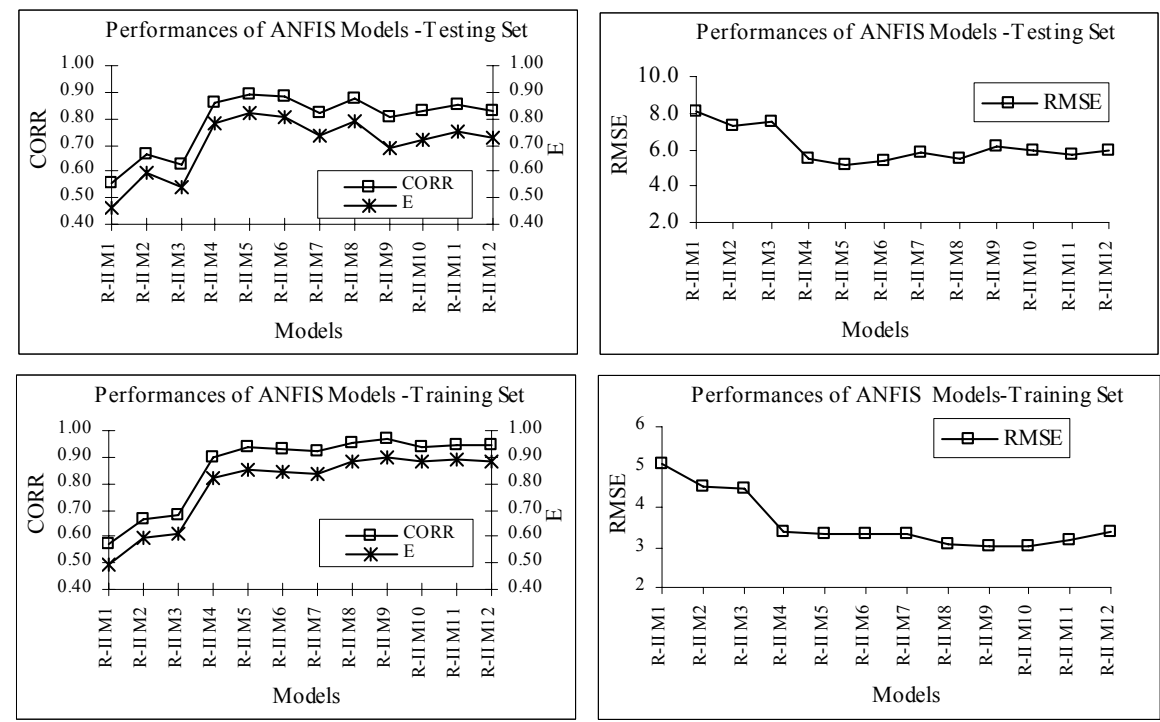

(b)

Fig. 7. Performances of ANFIS models, (a) Seyhan River, (b) Cine River.

Table 5. The performance of ANFIS models.

\begin{tabular}{lcccccc}
\hline Model & \multicolumn{3}{c}{ Testing Data Set } & \multicolumn{3}{c}{ Training Data Set } \\
\hline & RMSE & E & CORR & RMSE & E & CORR \\
\hline \multicolumn{5}{c}{ Seyhan River } \\
\hline R-I M2 ANFIS & 26.95 & 0.941 & 0.970 & 29.43 & 0.945 & 0.964 \\
\hline \multicolumn{6}{c}{ Cine River } \\
\hline R-II M5 ANFIS & 5.189 & 0.822 & 0.891 & 3.3084 & 0.856 & 0.940 \\
\hline
\end{tabular}



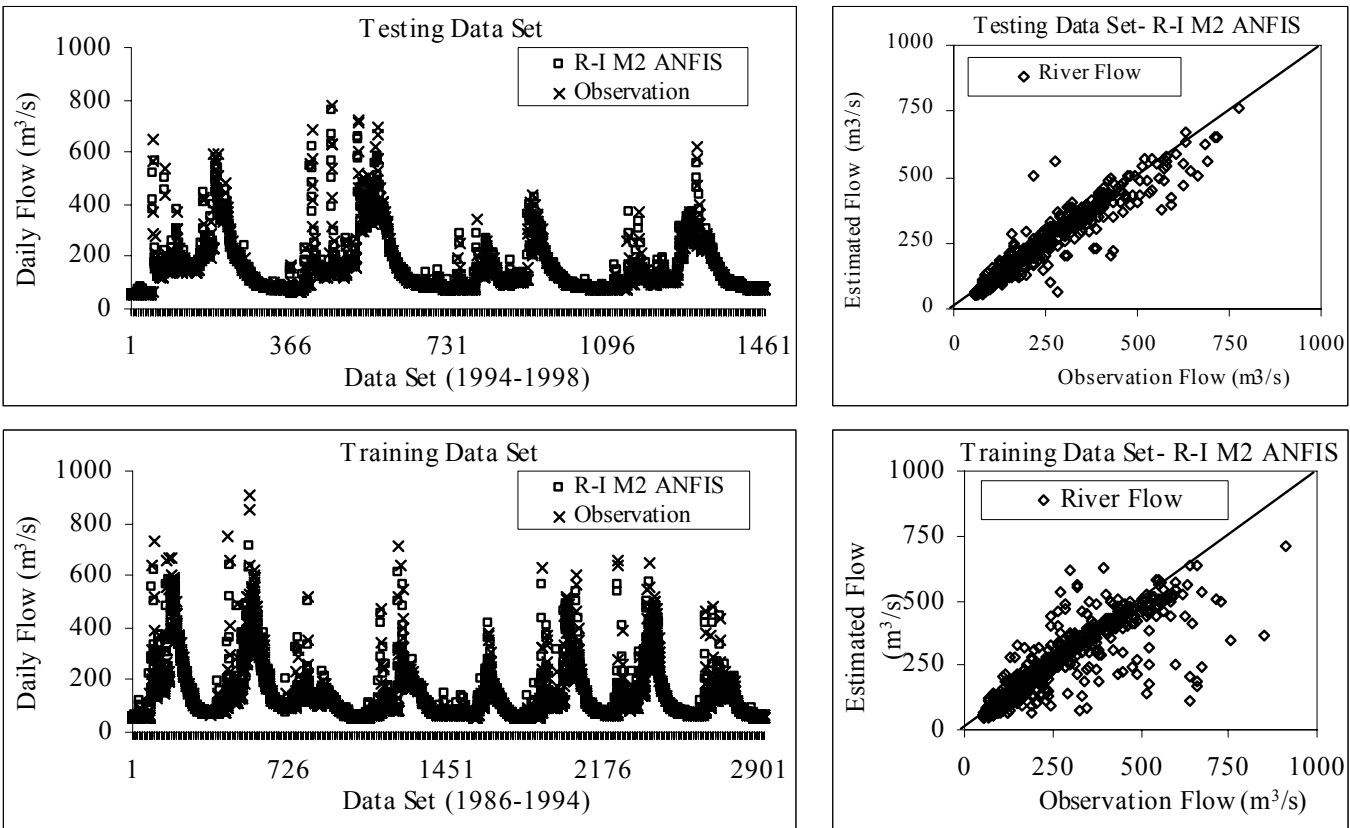

(a)
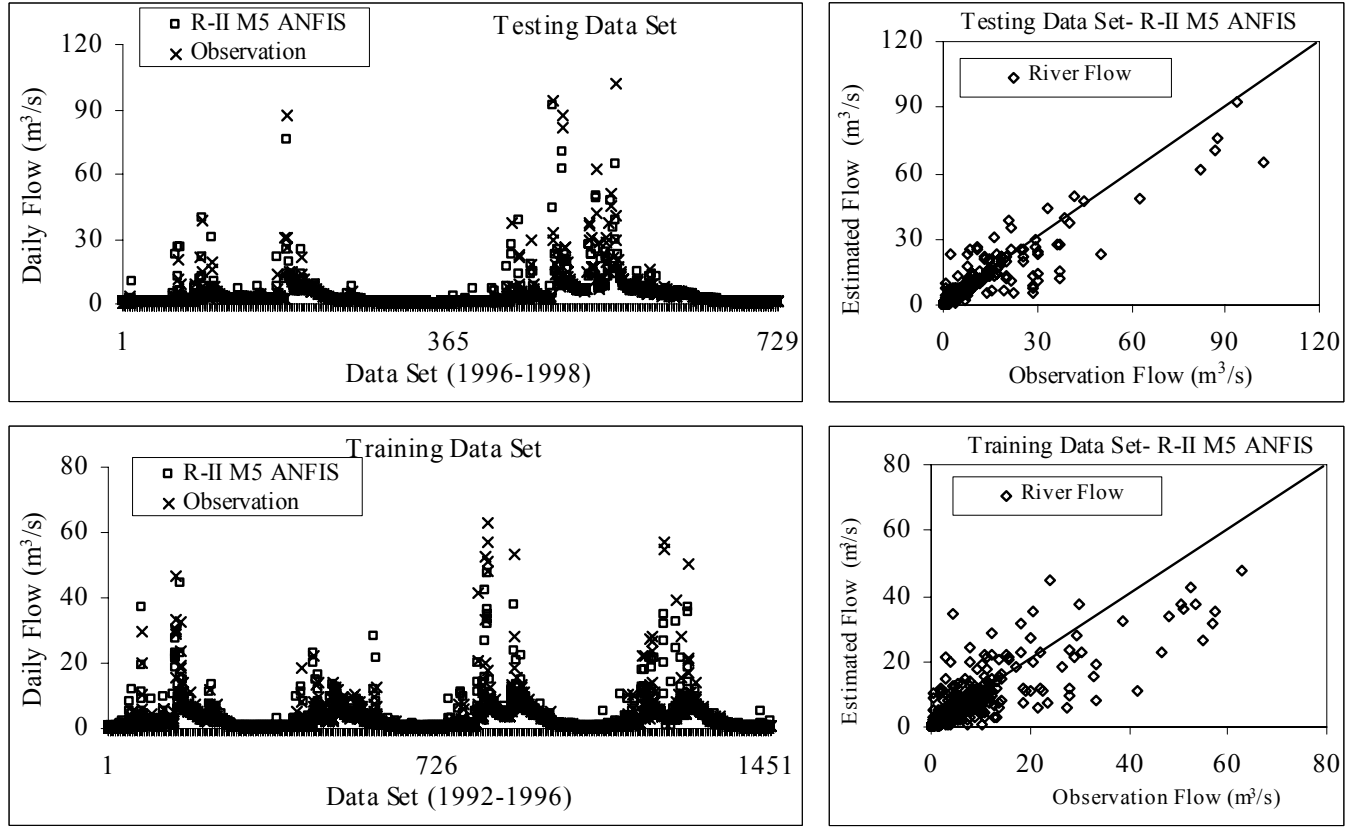

(b)

Fig. 8. The results of training and testing of models (a) R-I M2 ANFIS (b) R-II M5 ANFIS.

R-II M5 ANFIS was selected as the best fit river flow forecasting model for Cine River. The performances of the best fit ANFIS models for both stations are shown in Table 5.

It appears that the both ANFIS models generally are accurate and the values of RMSE are small enough, and correlation coefficients and efficiencies are very close to unity. The results of R-I M2 ANFIS model for Seyhan River and
R-I M5 ANFIS model for Cine River are compared with the observed flows in order to evaluate the performance of the training/testing of the model. Figure 8 shows the scatter diagrams of the estimated values of the training/testing of R-I M2ANFIS and R-II M5 ANFIS models and observed values.

The results of the ANFIS model demonstrate that the ANFIS can be successfully applied to establish accurate and reli- 

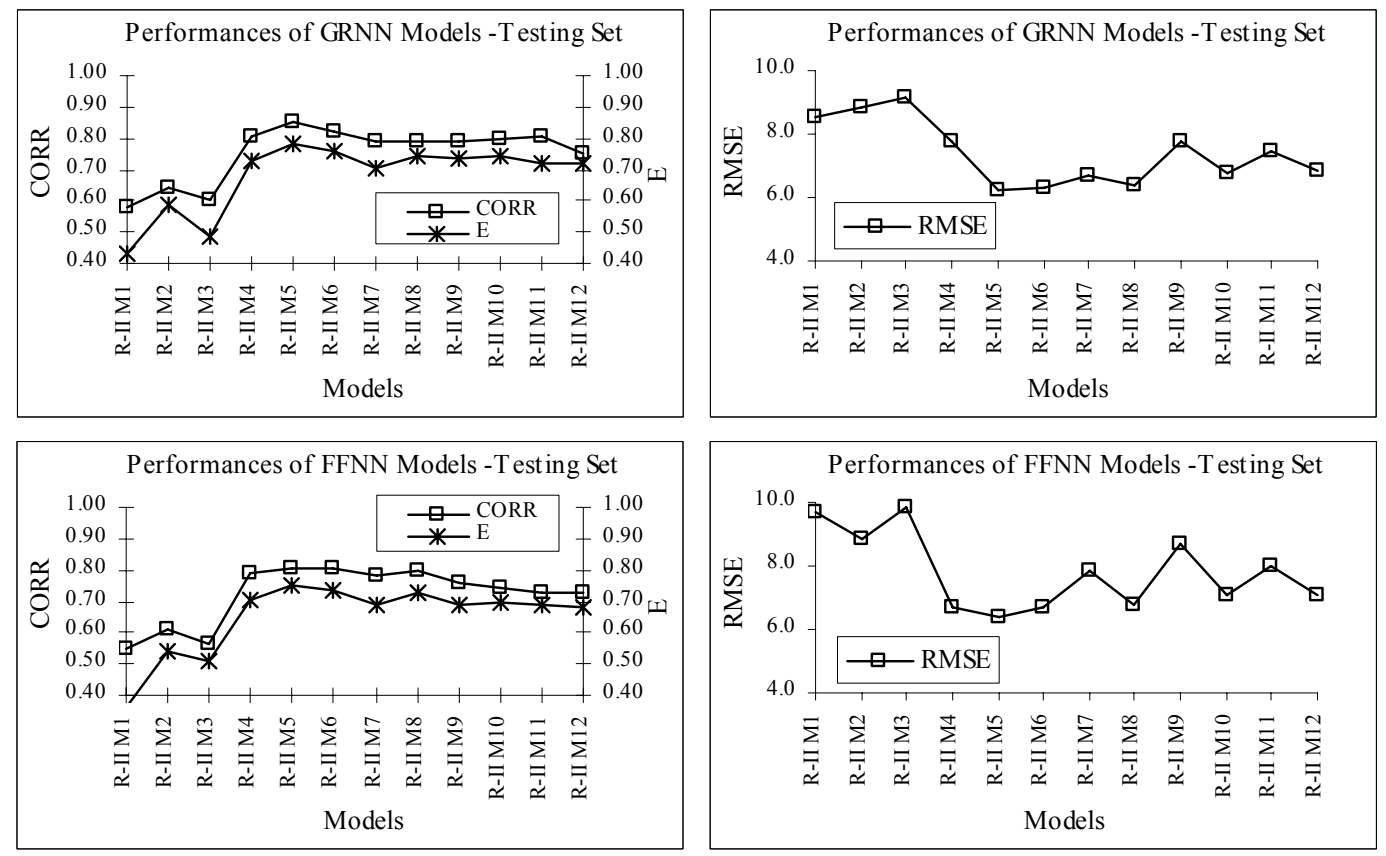

Fig. 9. The Performances of GRNN and FFNN models for Cine River.

able river flow forecasting models. In order to get a true and effective evaluation of the performance of ANFIS method, the models were also trained and tested by GRNN and FFNN methods.

\subsubsection{ANN Models}

In this study, secondly, the GRNN and FFNN methods are used for modeling of daily river flow. In the training and testing of ANN models, the same data set is used and performances of models are also evaluated and compared based on given above criteria. Figure 9 shows the performances of GRNN and FNNN models for Cine River. Moreover, Fig. 10 shows the performances of GRNN and FFNN models for Seyhan River.

Comparing the results of GRNN and FFNN models for Cine River given in Fig. 9, it said that the performances of the R-II M5 and R-II M8 models are near to each other and better than those of other models. The values of CORR and $\mathrm{E}$ of R-II M5 and R-II M8 models are higher than those of other models. Moreover, RMSE values of these models are also lower than those of other models. Although performances of R-II M5 and R-II M8 models are close to each other, results of R-II M5 models are better than R-II M8 models. As a result, R-II M5 GRNN and R-II M5 FFNN models were selected as the best fit forecasting models. The error backpragation algorithm and sigmoid activation function was used for the training and testing of FFNN model. The number of hidden neurons (5) in one hidden layer, the learning rate (0.05), the coefficient of momentum (0.7) and epochs (5000) were selected by trial and error method during the training process. On the other hand, as can be seen in Fig. 10, the values of the E and CORR of R-I M2 GRNN model for Seyhan River are higher than those of other models. In addition the value of RMSE of R-I M2 GRNN model is also lower than that of other models. As a result, R-I M2 GRNN model is selected as the best fit forecasting model according to criteria of performance evaluation. In order to get a true and effective evaluation, the best fit model structure having two input variables has also been trained and tested by FFNN. The FFNN model having two input variables was trained and tested using the same non-transformed data set. As can be seen in Fig. 10, the FNN model, which has five hidden neurons in hidden layer, has shown the best fit performance. The training parameters of the FFNN model such as, the learning rate (0.02), the coefficient of momentum (0.7) and epochs (2000) were selected by trial and error method during the training. The performances of forecasting models are given for both training and testing sets in Table 6 and Fig. 11.

Comparing the performances of R-I M2 GRNN and R-I M2 FFNN forecasting models for Seyhan River, it is seen that the value of the RMSE of the GRNN model is lower than FFNN model. In addition, the values of $E$ and CORR of the R-I M2 GRNN model are also higher than R-I M2 FFNN model. For Cine River, it can be said that the performance of R-II M5 GRNN model is better than R-II M5 FFNN model according to criteria given in Table 5. It may be noted that a trial and error procedure has to be performed for FFNN models to develop the best network structure, while such a procedure is not required in developing a GRNN model. The re- 

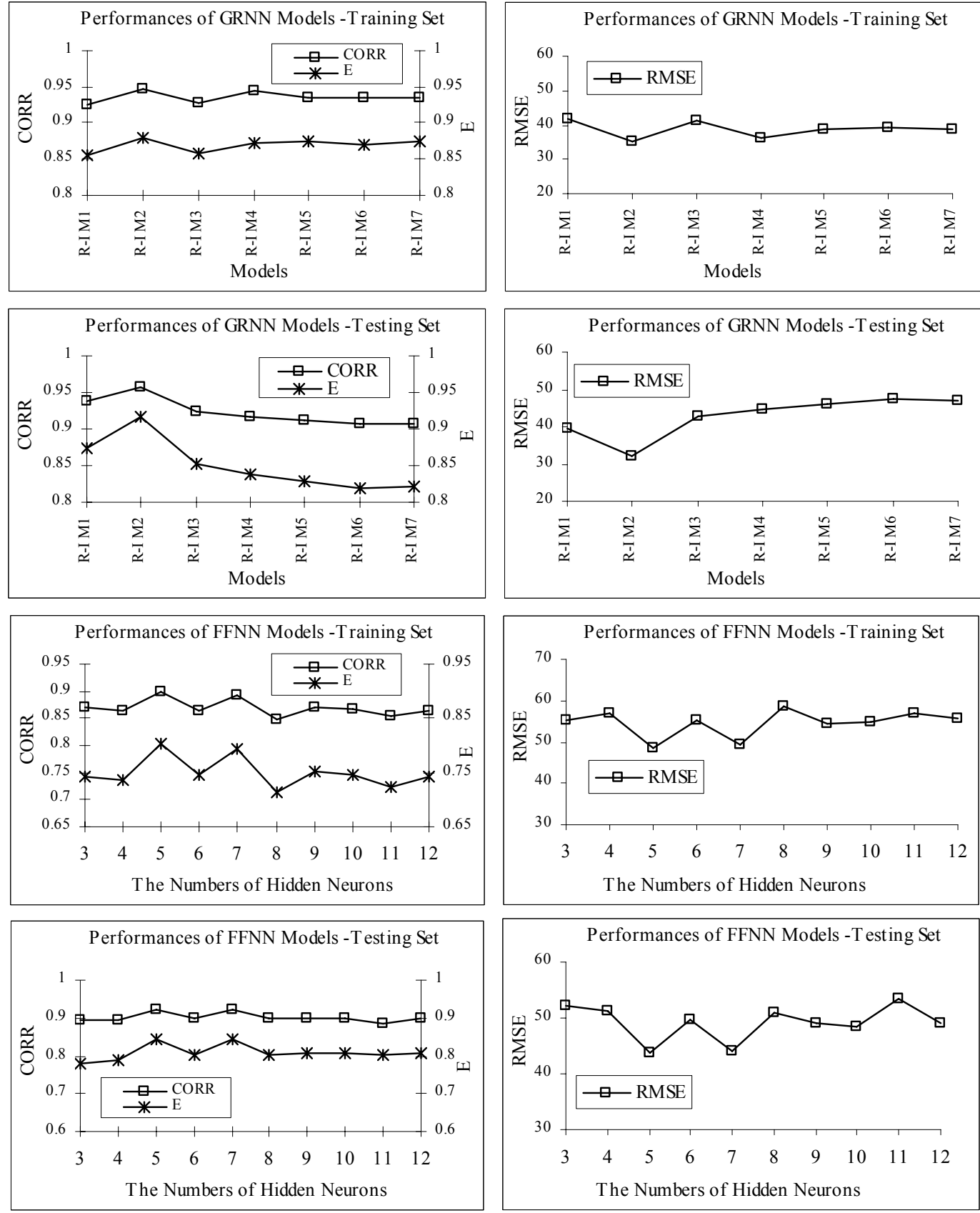

Fig. 10. The performances of GRNN and FFNN models for Seyhan River.

sults suggest that the GRNN method is superior to the FFNN method in the modeling and forecasting of the river flow. On the other hand, comparing the performances of ANFIS and ANN models for both stations, generally it is seen that the results of ANFIS models are better than ANN models. As a result, the results of training and testing of models demonstrate that ANFIS method is superior to ANN methods in forecasting of river flow. Moreover, it is said that ANFIS method can be successfully applied for river flow forecasting according to performance criteria.

\subsubsection{Autoregressive Model}

In order to get more accurate and reliable evaluation and comparison the best fit input structures were used to forecast the daily river flow by using traditional forecasting method. For the Seyhan river, AR (2) model includes two river flow 

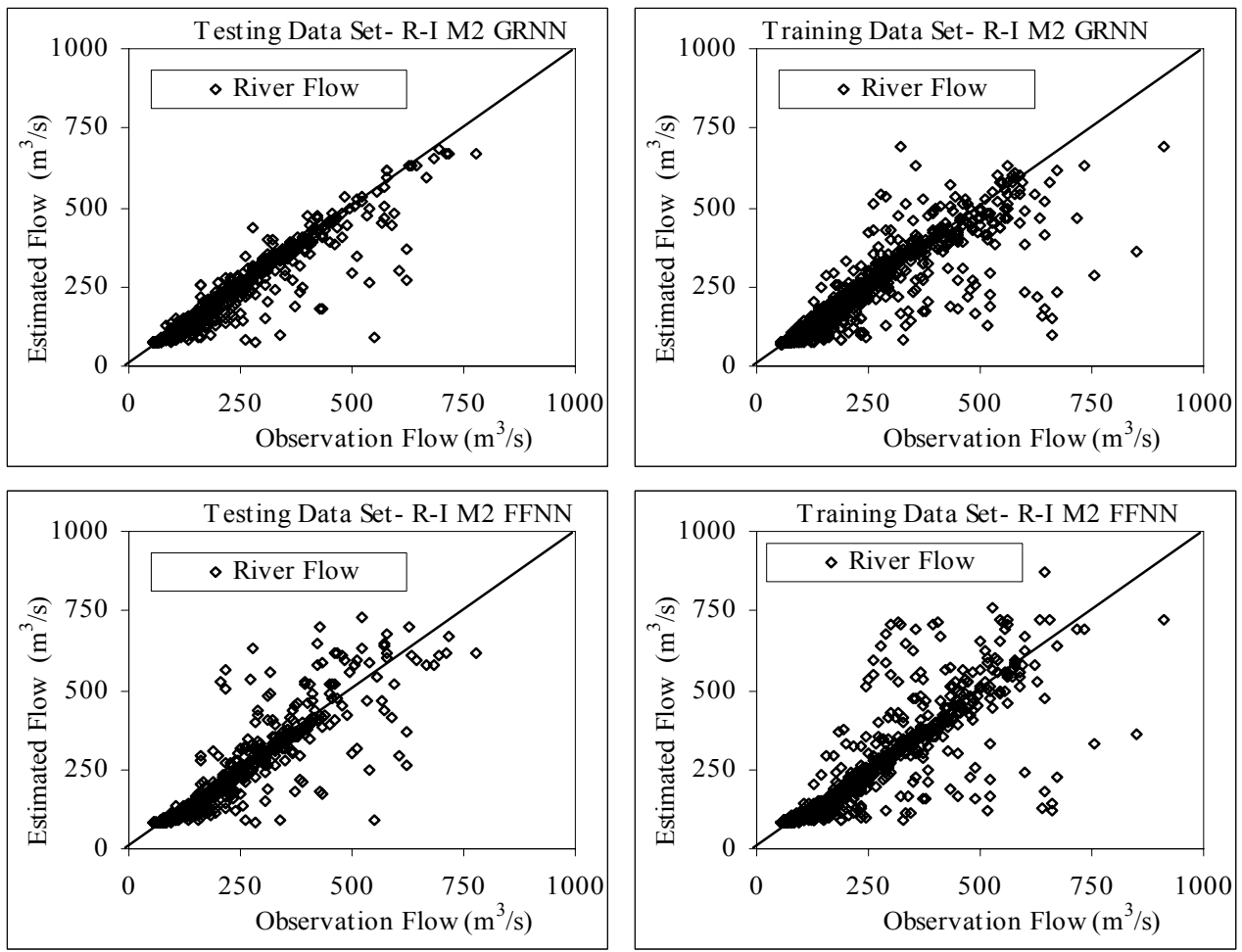

(a)
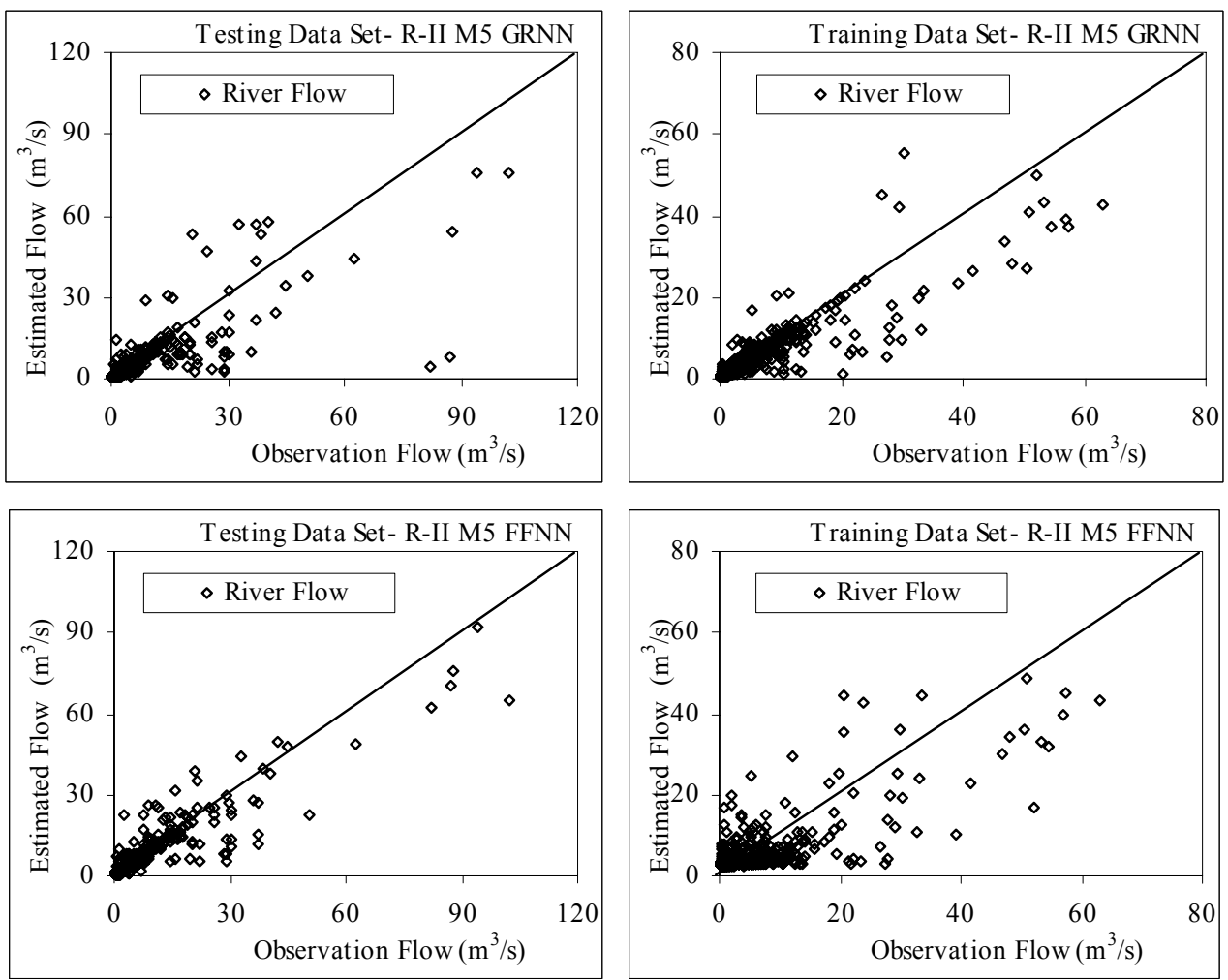

(b)

Fig. 11. Results of training and testing of GRNN and FFNN models (a) Seyhan River, (b) Cine River. 
Table 6. Comparison of performances of forecasting models.

\begin{tabular}{lcccccc}
\hline \multirow{2}{*}{ Models } & \multicolumn{3}{c}{ Testing Data Set } & \multicolumn{3}{c}{ Training Data Set } \\
& RMSE & E & CORR & RMSE & E & CORR \\
\hline \multicolumn{7}{c}{ Seyhan River } \\
\hline R-I M2 ANFIS & 26.95 & 0.941 & 0.970 & 29.43 & 0.945 & 0.964 \\
R-I M2 GRNN & 32.076 & 0.917 & 0.952 & 42.520 & 0.848 & 0.921 \\
R-I M2 FFNN & 43.830 & 0.845 & 0.924 & 48.475 & 0.803 & 0.900 \\
\hline & \multicolumn{7}{c}{ Cine River } \\
\hline R-II M5 ANFIS & 5.189 & 0.822 & 0.891 & 3.3084 & 0.856 & 0.940 \\
R-II M5 GRNN & 6.200 & 0.782 & 0.854 & 3.561 & 0.806 & 0.905 \\
R-II M5 FFNN & 6.347 & 0.751 & 0.804 & 3.878 & 0.765 & 0.847 \\
\hline
\end{tabular}

Table 7. Comparison of verification performances of models.

\begin{tabular}{lccccc}
\hline \multirow{2}{*}{ Models } & \multicolumn{5}{c}{ Verification Data Set } \\
\multicolumn{7}{c}{ Seyhan River } \\
\hline R-I M2 ANFIS & -9.12 & 69.96 & 33.972 & 0.873 & 0.935 \\
R-I M2 GRNN & 14.49 & 72.32 & 37.189 & 0.860 & 0.928 \\
R-I M2 FFNN & 15.31 & 77.48 & 43.595 & 0.808 & 0.899 \\
R-I M2 AR(2) & -11.90 & 72.27 & 39.344 & 0.823 & 0.914 \\
\hline \multicolumn{7}{c}{ Cine River } \\
\hline R-II M5 ANFIS & -10.39 & 74.26 & 6.322 & 0.817 & 0.894 \\
R-II M5 GRNN & -13.82 & 76.34 & 6.864 & 0.738 & 0.865 \\
R-II M5 FFNN & 14.21 & 78.54 & 7.551 & 0.717 & 0.826 \\
ARX Model & -13.95 & 77.06 & 6.990 & 0.741 & 0.854 \\
\hline
\end{tabular}

variables at two previous time lags in input vector, whereas for the Cine River ARX model has one river flow at one previous time lag and rainfall variables at the $(t)$ and $(t-1)$ time lags in input. Once the estimates of the traditional time series model coefficients have been obtained using the training data set, the model can be validated by computing the performance statistics during both training and testing data sets. The training and testing results of AR model for Seyhan River and ARX model Cine River are shown in Fig. 12.

\subsubsection{Verification of forecasting models}

The best fit ANFIS, GRNN, FFNN, AR and ARX models for both Seyhan River and Cine River are verified by verification data set. For Seyhan River, the verification set includes totally 731 daily river flow values at the time period 19982000 years. For Cine River, total 730 daily river flow and rainfall data records measured at the time period 1998-2000 years was used to verify the performance of forecasting models. The verification performances of all methods are given in Table 7.
For both stations, comparing verification performances of ANFIS, GRNN, FFNN, AR and ARX models, the values of RMSE of ANFIS models are lower than those of GRNN, FFNN, AR and ARX model. On the other hand, the values of $\mathrm{E}$ and CORR of ANFIS model are also higher than those of GRNN, FFNN, AR and ARX models. In addition, the best fit values of \%MERR and \%MP criteria were obtained from ANFIS models. Comparison of the verification results of models for Seyhan River and Cine River are demonstrated in Figs. 13 and 14, respectively.

\section{Conclusions}

In this study, applicability and capability of Artificial Intelligence techniques, ANFIS and ANN, and AR methods for daily river forecasting was investigated. To illustrate the capability of these approaches, Seyhan River and Cine River was chosen as a case study. Models having various input variables were trained and tested for both stations. The performances of the models and observations were compared 

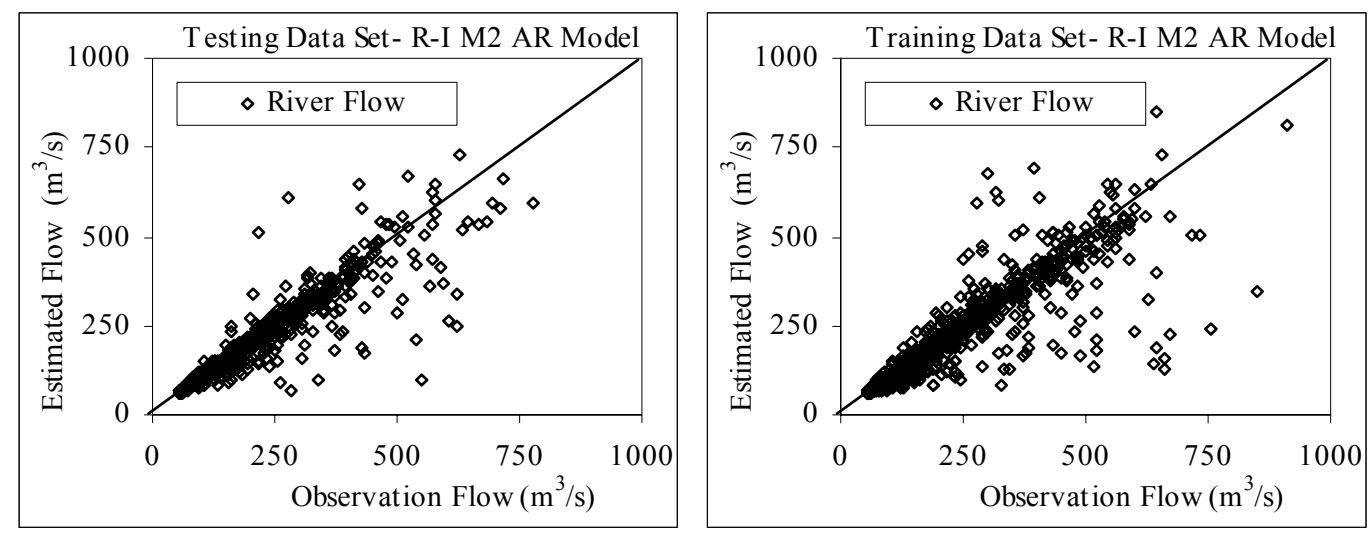

(a)
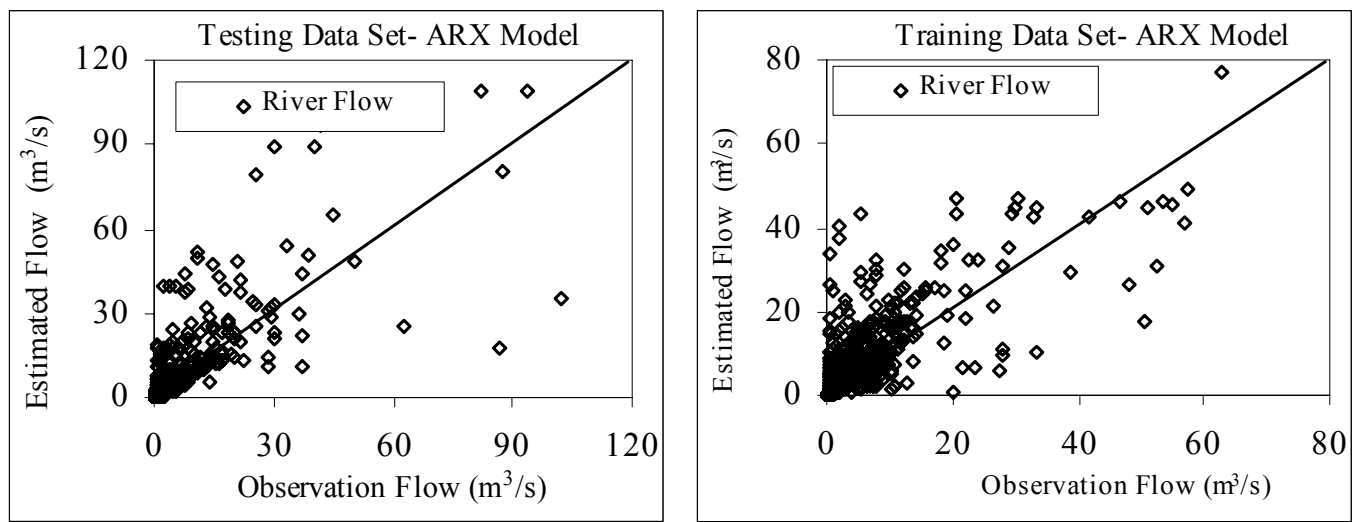

(b)

Fig. 12. The training and testing results of auto regressive models (a) Seyhan River, (b) Cine River.

and evaluated based on their performance in training and testing sets. For the Seyhan River, R-I M2 ANFIS model having two antecedent flow variables was selected as the best fit river forecasting model according to criteria of performance evaluation. Moreover, for the Cine River, R-II M5 ANFIS model, which has one river flow at one previous time lag and rainfall variables at the $(t)$ and $(t-1)$ time lags in input, has shown the best fit performance. The models were also trained and tested by GRNN, FFNN and Auto Regressive methods (AR method for Seyhan River and ARX method for Cine River) for the same set of data and results were reported to get more accurate and sensitive comparison. The results suggest that the ANFIS method is superior to the ANN and AR methods in the modeling and forecasting of river flow. It is said that the results of training, testing and verification of models demonstrate that ANFIS method is superior to ANN methods in forecasting of river flow according to criteria.

Acknowledgements. The author is grateful for Editor and Anonymous Reviewers for their helpful and constructive comments on an earlier draft of this paper.

Edited by: E. Toth

\section{References}

Arena, C., Cannarozzo, M., and Mazzola, M. R.: Multi-year drought frequency analysis at multiple sites by operational hydrology - A comparison of methods, Phys. Chem. Earth, 31, 1146-1163, 2006.

ASCE Task Committee.: Artificial neural networks in hydrology-II: Hydrologic applications, J. Hydrol. Eng., ASCE, 5(2), 124-137, 2000.

Box, G. E. P. and Jenkins, G.: Time Series Analysis, Forecasting and Control, Holden-Day, San Francisco, CA, 1970.

BuHamra, S., Smaoui, N., and Gabr, M.: The Box-Jenkins analysis and neural networks: prediction and time series modeling, Appl. Math. Model., 27, 805-815, 2003.

Celikoglu, H. B.: Application of radial basis function and generalized regression neural networks in non-linear utility function specification for travel mode choice modeling, Math. Comput. Model., 44, 640-658, 2006.

Celikoglu, H. B. and Cigizoglu, H. K.: Public transportation trip flow modeling with generalized regression neural Networks, Adv. Eng. Softw., 38, 71-79, 2007.

Chen, S. H., Lin, Y. H., Chang, L. C., and Chang, F. J.: The strategy of building a flood forecast model by neuro-fuzzy network, Hydrol. Process., 20, 1525-1540, 2006. 

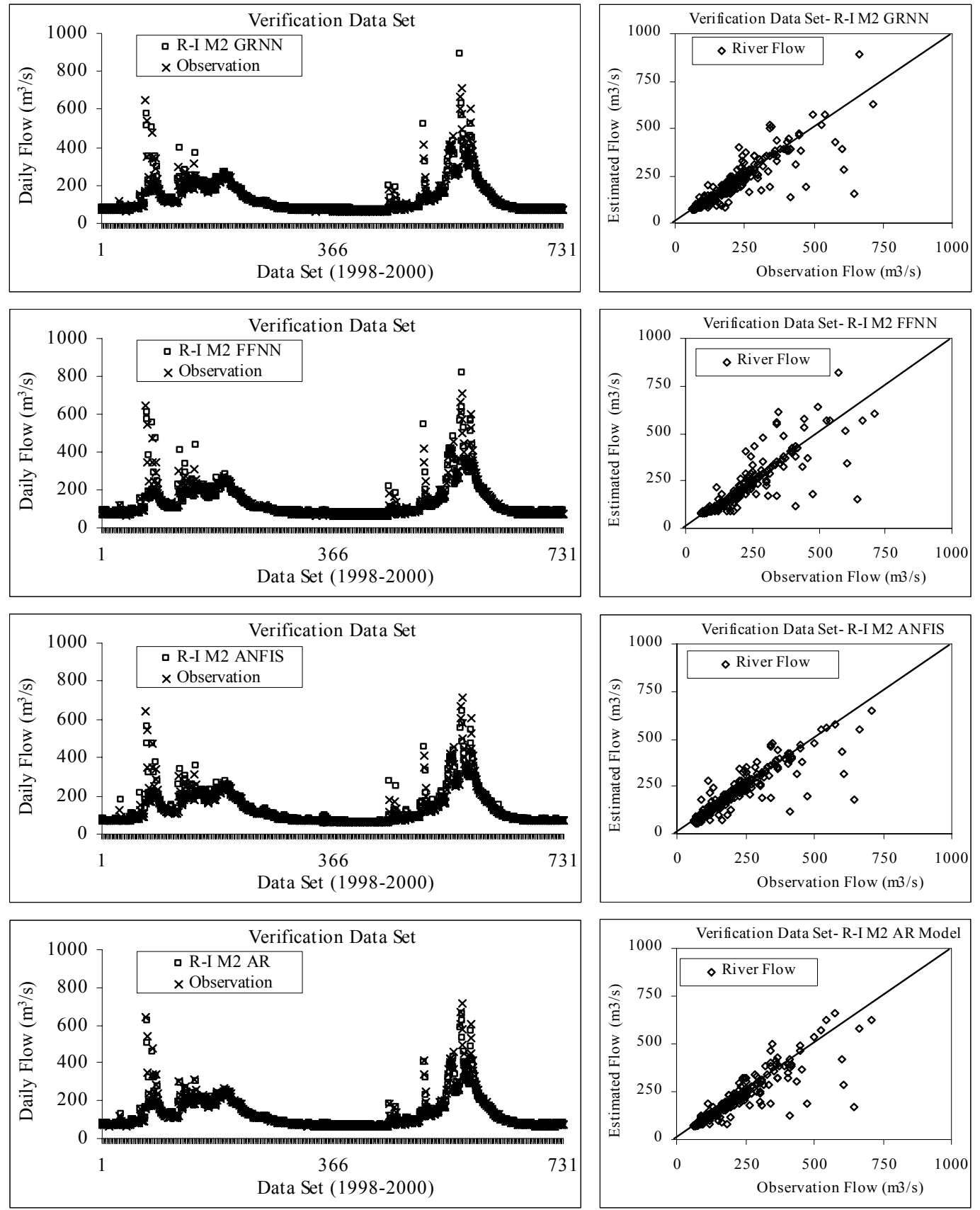

Fig. 13. Comparison of the verification results of models for Seyhan River.

Chang, F. J. and Chang, Y. T.: Adaptive neuro-fuzzy inference system for prediction of water level in reservoir, Adv. Water Res., 29, 1-10, 2006.

Chang, F. J, Hu, H. F, and Chen, Y.C.: Counter propagation fuzzyneural network for river flow reconstruction, Hydrol. Process., 15, 219-232, 2001.

Chang, F. J., Chang, L. C., and Huang, H. L.: Real-time recurrent learning neural network for stream-flow forecasting, Hydrol. Process., 16, 2577-2588, 2002.

Cigizoglu, H. K.: Generalized regression neural network in monthly flow forecasting, Civ. Eng. Environ. Syst., 22(2), 71-84, 2005.

Cigizoglu, H. K. and Alp, M.: Generalized regression neural network in modeling river sediment yield, Adv. Eng. Softw., 37, 63-68, 2006.

Dawson, C. W., Harpham, C., Wilby, R. L., and Chen, Y.: Evaluation of artificial neural network techniques for flow forecasting in the River Yangtze, China, Hydrol. Earth Syst. Sci., 6, 619-626, 2002 ,

http://www.hydrol-earth-syst-sci.net/6/619/2002/.

Dibike, Y. B. and Solomatine, D. P.: River Flow forecasting Us- 

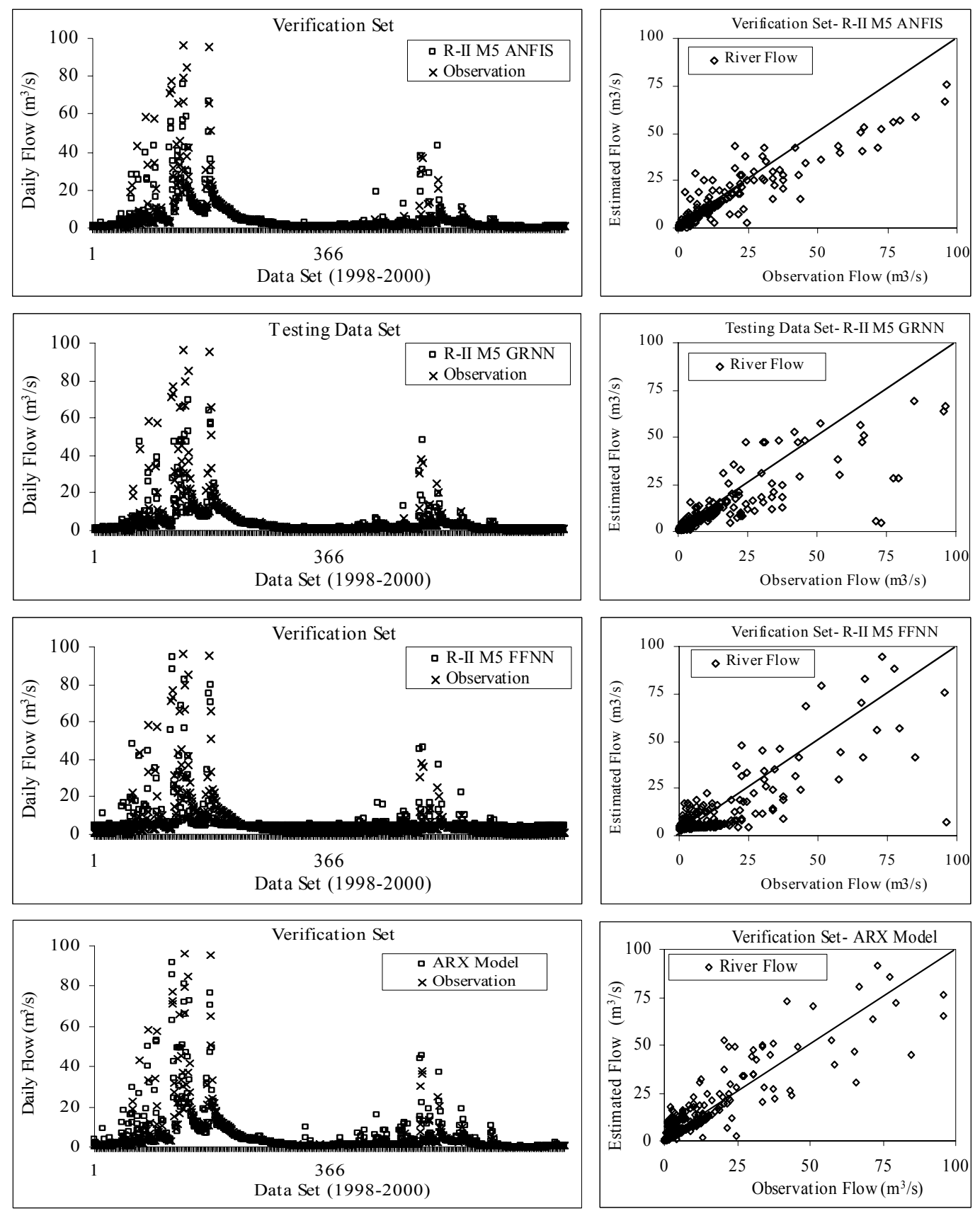

Fig. 14. Comparison of the verification results of models for Cine River.

ing Artificial Neural Networks, Phys, Chem. Earth (B), 26, 1-7, 2001.

Firat, M. and Güngör, M.: Estimation of the Suspended Concentration and Amount by using Artificial Neural Networks, IMO Technical Journal, 15(3), 3267-3282, 2004.

Firat, M. and Güngör, M.: River flow estimation using adaptive neuro fuzzy inference system, Math. Comput. Simulat., 75(3-4), 87-96, 2007.

Firat, M.: Watershed modeling by adaptive Neuro- fuzzy inference system approach. Doctor of Philosophy Thesis, Pamukkale Uni- versity, Turkey, 2007 (in Turkish).

Jain, A. and Kumar, A. M.: Hybrid neural network models for hydrologic time series forecasting, Appl. Soft Comput., 7, 585592, 2007.

Jang, J. S. R., Sun, C. T, and Mizutani, E.: Neuro-Fuzzy and Soft Computing, PrenticeHall, ISBN 0-13-261066-3, 607 s., United States of America, 1997.

Kim, B., Lee, D.W ., Parka, K. Y., Choi, S. R., and Choi, S.: Prediction of plasma etching using a randomized generalized regression neural network, Vacuum, 76, 37-43, 2004. 
Kisi, Ö.: Daily pan evaporation modelling using a model-fuzzy computing technique, J. Hydrol., 329(3-4), 636-646, 2006.

Komornik, J., Komornikova, M., Mesiar, R., Szökeova, D., and Szolgay, J.: Comparison of forecasting performance of nonlinear models of hydrological time series, Phys. Chem. Earth., 31, 1127-1145, 2006.

Liong, S. Y., Lim, W. H, Kojiri, T., and Hori, T.: Advance Flood forecasting for Flood stricken Bangladesh with a fuzzy reasoning method, Hydrol. Process., 14, 431-448, 2000.

Mahabir, C., Hicks, F. E, and Fayek, A. R.: Application of fuzzy logic to the seasonal runoff, Hydrol. Process., 17, 3749-3762, 2000.

Mohammadi, K., Eslami, H. R., and Kahawita, R.: Parameter estimation of an ARMA model for river flow forecasting using goal programming, J. Hydrol., 331, 293-299, 2006.

Nagy, H. M., Watanabe, K., and Hirano, M.: Prediction of Sediment Load concentration in Rivers using Artificial Neural Network Model, J. Hydr. Eng., 128, 588-595, 2002.

Nayak, P. C., Sudheer, K. P., and Ramasastri, K. S.: Fuzzy computing based rainfall-runoff model for real time flood forecasting, Hydrol. Process., 17, 3749-3762, 2004a.

Nayak, P. C., Sudheer, K. P., Rangan, D. M, Ramasastri, K. S.: A Neuro Fuzzy computing technique for modeling hydrological time series, J. Hydrol., 29, 52-66, 2004b.

Owen, J. S., Eccles, B. J., Choo, B. S., and Woodings, M. A.: The application of auto-regressive time series modeling for the timefrequency analysis of civil engineering structures, Eng. Struct., 23, 521-536, 2001.

Ramadhas, A. S., Jayaraja, S., Muraleedharan, C., and Padmakumar, K.: Artificial neural networks used for the prediction of the cetane number of biodiesel, Renew. Ener., 31, 2524-2533, 2006.
Sajikumar, N. and Thandaveswara, B.S.: A non-linear rainfallrunoff model using an artificial neural network, J. Hydrol., 216, 32-55, 1999.

Sudheer, K. P. and Jain, A.: Explaining the internal behaviour of artificial neural network river flow models, Hydrol. Process., 18, 833-844, 2004.

Tingsanchali, T. and Guatam, M. R.: Application of tank, NAM, ARMA and neural network models to flood forecasting, Hydrol. Process., 14, 2473-2487, 2000.

Thomas, H. A. and Fiering, M. B.: Mathematical synthesis of streamflow sequences for the analysis of river basin by simulation, in: Design of Water Resources Systems, edited by: Mass, A., Harvard University Press, Cambridge, MA, 459-493, 1962.

Toth, E., Brath, A., and Montanari, A.: Comparison of short-term rainfall prediction models for real-time flood forecasting, J. Hydrol., 239, 132-147, 2000.

Şen Z.: Fuzzy Logic and Foundation”, ISBN 9758509233, Bilge Kültür Sanat Publisher, Istabul, 172 pp., 2001.

Şen, Z. and Altunkaynak, A.: A comparative fuzzy logic approach to runoff coefficient and runoff estimation, Hydrol. Process., 20, 1993-2009, 2006.

Yevjevich, V.: Fluctuations of Wet and Dry Years. Part-I. Research Data Assembly and Mathematical Models, Hydrology Paper 1, Colorado State University, Fort Collins, CO, 1963.

Zadeh, L. A.: Fuzzy sets, Information and Control, 8(3), 338-353, 1965.

Zhang, G. P.: Time series forecasting using a hybrid ARIMA and neural network model, Neurocomputing, 50, 159-175, 2003. 